Siriwardena, M., Ross, A., Abbott, A. and Manewa, A., 2019. Apprentice perceptions of work based learning: Preliminary observations. In: Sandanayake, Y.G., Gunatilake, S. and Waidyasekara, A. (eds). Proceedings of the $8^{\text {th }}$ World Construction Symposium, Colombo, Sri Lanka, 8-10 November 2019, pp. 98 -106. DOI: doi.org/10.31705/WCS.2019.10. Available at: https://2019.ciobwcs.com/papers

\title{
APPRENTICE PERCEPTIONS OF WORK BASED LEARNING: PRELIMINARY OBSERVATIONS
}

\author{
Mohan Siriwardena ${ }^{1}$, Andrew Ross ${ }^{2}$, Andrew Abbott ${ }^{3}$ and Anupa Manewa ${ }^{4}$
}

\begin{abstract}
The degree apprenticeships programme involves a tripartite agreement involving the student apprentice, employer and the university. The programme introduced few years ago in the UK, which now caters to a significant number of apprentices in built environment related degree programmes. Although the Degree Apprenticeships involve a significant component of work based learning, limited evidence exist to justify Chartered Surveying Degree Apprenticeships Standard as a successful work based learning facilitator, mainly due to the scarcity of research. The findings of this paper are based on an ongoing research project, therefore is limited to evaluating Degree Apprenticeships apprentice perception of work based learning. Research method comprised of a literature review and the inspection of the guidance documents related to the delivery of the Degree Apprenticeships programme, followed by seven semistructured interviews with selected degree apprentices. Qualitative data analysis paved the way for identification of several success areas and the aspects that require further improvement. Lack of shared understanding among the three parties and the absence of explicit evidence of implementation of work based learning were noteworthy, and suggestions for improvement are proposed. Further research involving a wider sample of apprentices and employers suggested.
\end{abstract}

Keywords: Apprentice Perception; Degree Apprenticeships; Surveying Education; Work Based Learning.

\section{INTRODUCTION}

The Degree Apprenticeship (DA) programme introduced few years back in the United Kingdom (UK) has attracted a significant amount of attention. This is evidenced as there is a continuous improvement in number of active apprentices enrolled on such programs over the past few years (House of Commons, 2019). Whilst research reports on various aspects of the degree apprenticeship programme, research into the implementation of the work based learning element within the Chartered Surveying Degree Apprenticeship Standard is rare.

This paper reports on the preliminary findings of an attempt to evaluate the apprentice perception of work based learning, which is a part of an ongoing research project. The

\footnotetext{
${ }^{1}$ Department of Built Environment, Liverpool John Moores University, UK, M.L.Siriwardena@ljmu.ac.uk

2 Department of Built Environment, Liverpool John Moores University, UK, A.D.Ross@1jmu.ac.uk

${ }^{3}$ Department of Built Environment, Liverpool John Moores University, UK,

A.C.Abbott@2018.ljmu.ac.uk

${ }^{4}$ Department of Built Environment, Liverpool John Moores University, UK, R.M.Manewa@1jmu.ac.uk
} 
background to the degree apprenticeship programme in the UK is first introduced, followed by a detailed description of the current model. This is followed by a brief introduction to work based learning. The research method is presented next, followed by results, discussion and conclusions.

\section{DEGREE APPRENTICESHIPS INITIATIVE}

The skills shortage in the UK's workforce is well recognised. The skills gap in the built environment was highlighted in a review of industry reports and government publications (CITB, 2017). These skills gaps appear to be worsened by the perceived knowledge and abilities of graduates leaving higher education (HE) and the expectations and demands of business and employers (Hernández-March, Martín del Peso, and Leguey, 2009).

The construction industry being a labour intensive industry is significantly affected as a result. On the other hand, the vital role of the construction industry in the context of the UK economy is well documented. Publications such as the Government Industrial Strategy (BEIS, 2017) further reinforces the important role of the construction industry in the future economy of UK. The UK's universities are a key supplier of the skilled workforce to the construction industry but as a result of the higher education funding reviews which took place during the latter part of the last decade (Browne, 2010), significant increases in the tuition fees were introduced. As a result, employability of graduates became a key criterion for course selection as well as performance measurement of universities. Within this backdrop, Degree Apprenticeships were introduced as a way of developing the skilled workforce.

The UK government pledged itself to continue with an ambitious programme of reforms to apprenticeships, which were set out in 2015 and were informed by the 2011 Wolf Review of vocational education. The Wolf Review's (Wolf, 2011) findings impugned a system where too many apprentices were locked into dead-end jobs and where many high-quality apprenticeships were rare. The drivers behind the government's apprenticeship reforms are cited by the Skills Funding Agency (SFA) as being:

1. A need to improve productivity through up-skilling

2. A desire to force employers to invest more in high-quality training

3. An ambition to improve social mobility and create more opportunities for young people

4. The ongoing policy directives around getting universities and business to collaborate

As well as increasing the quantity of apprenticeships available, the government aimed to increase their quality by setting up the Institute for Apprenticeships (https://www.instituteforapprenticeships.org/). This new body, which was launched in April 2017, was made up primarily of employers who were responsible for setting the new apprenticeship standards, which were developed and proposed by employer consortia (Trailblazer groups) in consultation with educational providers.

The Richard Review of Apprenticeships (Richard, 2012) set out to define the future of apprenticeships in the UK and defined a vision of how apprenticeships could meet the needs of the changing economy. The strategy also aimed at redefining the shape of the existing system and examine how the apprenticeship system must work towards the betterment of the UK economy in future. In his independent report, Richard makes recommendations to the UK government to improve the quality of apprenticeships and 
make them tailored to the needs of employers. Some of the recommendations of Richard (2012) as noted by Dawson and Osborne (2018) include:

- A redefinition of apprenticeships: Where they should be targeted only at those who are new to a job or role that requires sustained and substantial training.

- A new focus on the end goal of an apprenticeship - what the apprentice is capable of doing when they complete their training - and giving more freedom in the design of the actual process as to how they get there. Trusted, independent assessment is key where recognised industry standards should form the basis of every apprenticeship. RICS is the expected standard for the surveying apprenticeships.

- All apprentices should reach a required minimum standard in English and Mathematics before they can complete their apprenticeship.

- Government funding must create the right incentives for apprenticeship training. The purchasing power for investing in apprenticeship training should lie with the employer. This has been handled by the levy system.

- Greater diversity and innovation in training - with employers and government safeguarding quality.

\section{DEGREE APPRENTICESHIPS MODEL}

The DA programme involves a tripartite agreement involving the student (apprentice), employer and the university. Students enrolled on degree apprenticeships programme share their time between the workplace and flexible university study. $80 \%$ of their time can be spent on their workplace activities catering to work based learning, training etc and the rest of $20 \%$ require to be devoted to off-the-job training, learning undertaken outside of their day-to-day workplace role that contributes to the apprenticeship such as university learning, research, attending Continuous professional Development (CPD) activties etc.

The DA scheme is designed by employers, universities and professional bodies, which aims to deliver high-tech and high-level skills and offer an alternative to a traditional degree course (National Audit Office, 2016). However, current accountability frameworks may result in an unnecessary confusion around the roles and responsibilities of individual actors associated with degree apprenticeship delivery resulting in a missed opportunity to maximise the value arising from the tri-partite delivery relationship (Lambert, 2016).

Developments in the area of employer engagement in academic degree programs have been inconsistent and difficult to predict. Although there are established models of industry-academia collaboration in different sectors (Gorschek, Garre, Larsson, and Wohlin, 2006), many of these relate to research interaction rather than skills and capacity building. The Degree Apprentice initiative is one of the first structured frameworks to formally drive the collaboration of industry and academia in large scale educational delivery (Ross and Riley, 2018).

Outputs of the DA programs are designed by the degree apprenticeships standards that have in turn been designed by the industry. Consequently, industrial partners are stakeholders in the development of knowledge, skills and behaviours within the Degree Apprentice. The University component of the apprentice's End Point Assessment (EPA) 
is a Level 6 award, based upon a curriculum that is delivered to full and part time students uniformly.

Although the Degree Apprenticeships require (and promise) the provision of work based learning, evidence of Chartered Surveying Degree Apprenticeships Standard as a successful work based learning facilitator is lacking, mainly due to the scarcity of research. Hence, there is a need for a study to address this gap in knowledge. This research aims to evaluate the preliminary findings in relation to the perceptions of current degree apprentices in relation to the work based learning element of the degree apprenticeship provision.

\section{WORK BASED LEARNING}

Work based learning (WBL) has become an umbrella term and occur in many forms. Lester and Costley (2010, p.562) state that the term 'work-based learning' as "any learning that is situated in the workplace or arises directly out of workplace concerns". Moreover, they have noted that although most of the work based programmes are a combination of teaching and research elements, facilitation of active and enquiry-based learning from purposive (work) activity is a cornerstone of work based learning.

In relation to higher education, Garnet (2016) observes that WBL is used to describe higher education programmes of study where the learning takes place primarily and continue throughout for the purposes of work. A much more inclusive and overarching definition in relation to higher education is provided by Gibbs and Garnett (2007, p. 411) who define WBL as "a learning process which focuses university-level critical thinking upon work (paid or unpaid), in order to facilitate the recognition, acquisition and application of individual and collective knowledge, skills and abilities, to achieve specific outcomes of significance to the learner, their work and the university". Having considered the available definitions for WBL this study is closely aligned with the definition provided by Gibbs and Garnett (2007).

\section{RESEARCH METHOD}

A literature review was performed to gain an understanding of the inception and the evolution of the current degree apprenticeship provision in the UK in general and, in particular to the built environment sector. A critical evaluation of work base learning was also undertaken appropriately.

Document reviews were carried out to explore the details, requirements and the process of Chartered Surveying Degree Apprenticeships standard. Seven (07) semi-structured interviews were conducted with current degree apprentices who follow the chartered surveying degree apprenticeships standard at a university in the Northwest of UK, to gain an insight into the current status of work based learning within the current degree apprenticeships provision. A list of questions were devised to elicit responses from the subjects to best uncover the information required for the study (Stewart, Campbell, McMillan, and Wheeler, 2019). These semi-structured interviews are more formal than the unstructured interview whereby there are several specific topics which the questionnaire covers. The interview uses both open and close ended questions but there was no specific order to the questions again using the interviewer's experience to decide on exactly how the interview should be conducted. The task is to discover the most possible in relation to the subject area (Naoum, 2013). 
Seven apprentices (07) belonging to six (06) employers were selected to take part in the study. They were geographically spread across the Northwest of England and considered to be representative of the population of employers delivering degree apprenticeships in the quantity surveying profession.

Qualitative and thematic data analysis was conducted. The qualitative data from the interview transcripts were initially structured and analysed using categorisation of themes, and the conclusions derived accordingly.

\section{RESULTS AND DISCUSSION}

The apprentices' perspectives on current setting of the DA programme, fit for purpose of in-class or university (theoretical) learning in relation to practice (work based learning), were assessed to evaluate the current model and identify further improvements. Empirical data collected can be presented under several themes as discussed below.

\section{- Employers' attitude and awareness of the degree apprenticeship framework}

Employers' disconnect with the degree apprenticeship framework was one of the noteworthy aspects that emerged from these interviews. For example, comments such as "my annual appraisal does not take into account university work... like we always say, textbooks are different from the real world" reflects the limited awareness of employers on Degree Apprentice requirements.

Moreover, most of the in-house training programs are not designed to align with the required skills of the EPA, hence not being aligned with the work based learning requirements of degree apprenticeship framework. This issue derived from one of apprentices who further explained that

"my company has a developmental programme. There are competencies that I need to hit as well. But that is more tailored toward each person's individual role, not everyone goes round the houses and does everything. It's not one programme for everyone it is a tailored towards whatever role you are in".

In a way this is commonplace between education and workplace that the work focus tends to be narrower than the naturally wider educational curriculum. As a result, apprentices tend to reside within a specific comfort zone. This was confirmed by few of the interviewees as "I do not have plans to get exposure to the estimating side of things. I quite like what I do."

More importantly, the attitude of an employer towards university and EPA can be challenging: "I suppose it depends who your boss is. My boss says I have never been to university, all I've got is GCSEs and that, you don't need to do all that ....'"This displays a prevalent attitude in the workplace that what is taught in university is irrelevant to the real world business objectives.

However, it is worth noting that there are those who disagreed with the above-mentioned position. Some of the interviewees suggested that their employers are reliant on university to provide the knowledge:

"My company expects me to get the knowledge from university - there is no learning structure inside the company. They expect a certain level of knowledge like construction technology." 
The findings such as 'employers disconnect with DA programme', training not aligning with the APC requirements, attitudes on university education, letting students to learn/master on one single or limited number of skills rather providing overarching support, reflects employers limited awareness of current Degree Apprentice framework.

\section{- Relevance of education curriculum towards achieving work place learning}

One view is that learning in the workplace tends to be 'hands on' helping a more experienced colleague. To confirm this argument one apprentice noted that

"Our Managing Director wants to get me involved in filling out demolition orders before work starts on site. When I told him I don't have any experience in procurement he said "well you can help me with this then".

However, the above observation should not be interpreted as if university curriculum is not fit for purpose as another apprentice clearly explained that

"Yes, university is relevant to my work. Most of the stuff that I see as relevant is such as we went through procurement and sustainability to promote sustainability throughout your specifications. The measurement side that you do I don't really do that work. We have a whole team that do measurement so if I was doing one of their jobs then it would definitely be relevant."

Supportively, "You use things from the course without realising most of the time." Demonstrates the importance of education curriculum in work based learning. Therefore, it is worth further investigating what makes one think that it is irrelevant. One possible explanation is the mismatch in terms of timing of the delivery rather with the content of the course. Comments below do shed some light in this regard.

"I would say the first couple of years in university was not relevant. I don't think they were up to speed in terms of what you were doing on the job. There was stuff I needed to know straight away in terms of tendering and procurement. That came in maybe last year so maybe the speed of learning isn't aligned."

The fit for purpose of the academic curriculum in work based learning is argued and both positive and negative perceptions were noted in terms of contents of the curriculum and the timing of delivery.

\section{- Assessment in the workplace}

Given the strong connection between learning and assessments, apprentice views were sought on possible changes to the current university assessments regime by conducting some of the assessments within the workplace. Whilst the responses were mixed, it was obvious that it did generate a significant amount of reflection on the part of the apprentice.

\footnotetext{
"Assessment in the workplace - how would that work with confidentiality and stuff like that? Yeah but I'm thinking if it is part of my course such as a validation of account with subcontractors. Certain modules...I don't know. I don't know what benefit you are trying to get out of it are you trying to make it more align it more with the industry. I can just issue you with work that I have already done. Yeah, I think that could have some benefit, definitely because if you are doing something very similar, yeah. I think that would be very good, when you go out and see stuff yeah, I think you could learn more. Actually, doing something practical, yeah."
}

Most apprentices acknowledged the value of such approach and the reservations were more related to the practicalities of such an approach. 
"If part of the university assessment took place in work I think it would be interesting but it is very subjective. When you are doing assessments you want to be objective so it is easy to mark against. Also, there is a problem with confidentiality."

It also became clear that for such an approach to succeed, a significant level of trust building is required between the apprentice and the employer.

"I would not like some university assessments to be done in work by my employer. I don't like the sound of that. It will make the assignment easier but it gives the employer reason to see your mistakes."

The apprentices' perceptions on assessments in work place is interesting. Few of the apprentices agreed with such approaches as it will help them to understand the theory in practice, provide a room to create good bond between employer and the apprentice. However, one argued that it will help employers to detect the apprentice's mistakes easily, which the apprentice perceived as a possible threat.

\section{- Work life balance for student apprentices}

Degree apprenticeship route requires the apprentice to study for a Level 6 degree qualification, and also to prepare and submit themselves to the Assessment of Professional Competencies (APC) as their end point assessment. The nature of workload pressures was also part of the investigation of this research.

Responses were varied and demonstrated a level of correlation with the level of maturity of the apprentice. The more mature apprentices seem to respond well to the challenge.

"My work life balance is good. I like being busy I go to the gym all the time as well."

However, several challenges were also highlighted by the respondents.

"My work life balancing - I found the last semester to be quite challenging, in parts in work and also university because I think you get to a point in the third year where everything racks up so you are expected to do different work and also the modules in university get harder so I found last year quite hard."

\section{- Acquiring RICS professional competencies}

Submitting to the end point assessment is a requirement of the degree apprenticeship scheme. Work based learning element of the degree apprenticeship scheme is expected to provide the leading support in this regard. Preliminary observations indicate more progress is required.

Where there is progress, reflection appear to be lacking. For example, in instances where there are company mandated route(s) for achieving RICS competencies, there is a lack of engagement in terms of the reflective nature required.

"My counsellor picks the competencies. I'm clear on the way forward (but) the RICS website is hard to follow." Although reflection is expected to be an integral part of learning, it appears that such an activity is seen as an added burden by some of the apprentices.

"I do not do the reflection. I see this as extra which is too much work." However, it would be wrong to conclude that the attitude towards working to acquire the necessary competencies is all negative. Perhaps more guidance is needed. 
"I need examples of the knowledge required to pass the APC-you choose your case study and have to know it inside out. I don't know what my case study is. As soon as I know that I can start... My supervisor is giving me a case study but I do not have it yet."

\section{- Do you get the $20 \%$ off the job training?}

Degree apprentices are required to obtain $20 \%$ off the job training during their entire apprenticeship. During term-time, this equates to one day of attending lectures and tutorials at the university. This research investigated the implementation of the $20 \%$ off the job training during non-term time. Findings painted a mixed picture and explicit evidence of implementation is sketchy.

"Doing my job if I need something else in order to fill out a competency I am allowed to go and do that. There are a couple of whole day events for CPD -7 and a half hours CPD. Some of them are really good."

"Yes, my manager has always been happy for me to continue learning and they do give me the time. My manager has always been happy for me to continue learning. Obviously, it is part of my framework."

Whilst comments such as the one above demonstrate explicit employer support, there appear to be some level of confusion in terms of the purpose of $20 \%$ off the job training.

"It depends who you work for. If I need a day off to revise, they give it to me. It depends on your employer really."

The issue with these positive comments about being given sufficient time to study is that there is no significant evidence that any of the students are in fact receiving the required equivalent of one day per week off the job training during non-term time. This is made worse by the fact that many of the apprentices who are at the early years of their apprenticeship in particular, expressing a lack of awareness of the need and the entitlement of $20 \%$ off the job training during non-term time.

\section{CONCLUSIONS}

A key expectation of the degree apprenticeship scheme is that it will facilitate work based learning for the apprentice. Following a review of literature and related documentation, this research attempted to evaluate the apprentice perceptions on the status of work based learning within a selected group of apprentices.

Preliminary observations indicate that whilst there are number of success areas, the extent of room for improvement is also significant. Removal of the burden of having inherit graduate debt and the opportunity to obtain work experience whilst studying for a degree still appear to be the core drivers for engaging in the degree apprenticeship programme by the apprentices. However, evidence of implementation of the specific activities as mandated by the degree apprenticeship standard, and the attainment of work based learning is rather sketchy. This is not to conclude that the activities are not taking place or that work based learning is non-existent, but a recognition that the evidence should be made more explicit. Development of a collaboratively authored and accessed, user friendly, information system may help to overcome some of the difficulties in this regard. Improving the shared understanding of the purpose and the requirements of the degree apprenticeship scheme among apprentices, employers and the university, and development of bespoke work based learning plans based on the work context of each apprentice are some of the suggestions to improve the current delivery. Furthermore, 
future research requires a greater sample of apprentices be included and the employers' and university staff perceptions be taken into account in order to arrive at more holistic understanding of the current status.

\section{ACKNOWLEDGEMENTS}

Support received from the curriculum enhancement internship fund of Liverpool John Moores University, UK, is acknowledged.

\section{REFERENCES}

BEIS (Department for Business, Energy and Industrial Strategy). 2017. Industrial Strategy: Building a Britain Fit for the Future. London: HM Government.

Browne, J., 2010. Securing a sustainable future for higher education: an independent review of higher education funding and student finance, Department for Business, Innovation and Skills

CITB. 2017. Industry insights. Construction skills network forecast 2017-2021. Experian.

Dawson, S., and Osborne, A., 2018. Reshaping built environment education: The impact of degree apprenticeships [online], Project Report. Council of Heads of the Built Environment, Available from http://nrl.northumbria.ac.uk/id/eprint/36461 [Accessed 12 Aug 2019]

Garnett, J., 2016. Work-based learning: A critical challenge to the subject discipline structures and practices of higher education. Higher Education, Skills and Work-Based Learning, 6(3), pp.305-314.

Gibbs, P. and Garnett, J., 2007. Work-based learning as a field of study. Research in Post-Compulsory Education, 12(3), pp.409-421.

Gorschek, T., Garre, P., Larsson, S. and Wohlin, C., 2006. A model for technology transfer in practice. IEEE software, 23(6), pp.88-95.

Hernández-March, J., Del Peso, M. M., and Leguey, S., 2009. Graduates'skills and higher education: The employers' perspective. Tertiary Education and Management, 15(1), pp.1-16.

House of Commons., 2019. Apprenticeship Statistics: England, Briefing paper, Number 06113.

Lambert, S. 2016. Are current accountability frameworks appropriate for degree apprenticeships? Higher Education, Skills and Work-based Learning, 6(4), pp.345-356.

Lester, S. and Costley, C., 2010. Work-based learning at higher education level: value, practice and critique, Studies in Higher Education, 35(5), pp.561-575.

Naoum, S., 2012. Dissertation research and writing for construction students. $3^{\text {rd }}$ ed. Oxon: Routledge.

National Audit Office, 2016. Delivering Value through apprenticeships programme, Report by the Comptroller and Auditor General - prepared for the Department of Education, UK.

Richard, D., 2012. Richard review of apprenticeships. London: Business, Innovation \& Skills.

Ross, A. and Riley M., 2018. Degree apprenticeships: Disruption or business as usual, Proceedings of the Annual Conference of the Associated Schools of Construction, Minnesota.

Stewart, V., Campbell, M., McMillan, S.S., and Wheeler, A.J., 2019. Postgraduate work-based learning: a qualitative study. Higher Education, Skills and Work-Based Learning, pp.637-649.

Wolf, A., 2011. Review of Vocational Education-The Wolf Report, Department for Education, UK. 